\title{
Analysis and Studies for Receiving Pesticides and Herbicides from Wastes from Production
} \author{
Mirzaev $^{6}$, AS Naukenova ${ }^{6}$, A Tleuova ${ }^{6}$ and S Shapalov ${ }^{6}$ \\ ${ }^{1}$ Doctor of Technical Sciences, M Auezov South Kazakhstan State University, Russia \\ ${ }^{2}$ Doctoral student, M Auezov South Kazakhstan State University, Russia \\ ${ }^{3}$ Masters of Economics, M Auezov South Kazakhstan State University, Russia \\ ${ }^{4}$ Doctor of Technical Sciences, M Auezov South Kazakhstan State University, Russia \\ ${ }^{5}$ Candidate of Technical Sciences, M Auezov South Kazakhstan State University, Russia \\ ${ }^{6}$ Associate Professor, M Auezov South Kazakhstan State University, Russia
}

KT Zhantasov ${ }^{1}$, SSh Shalataev ${ }^{2 *}$, DM Zhantasova ${ }^{3}$, DS Berzhanov ${ }^{4}$, MK Zhantasov $^{5}$, NK Sarypbekova ${ }^{6}$, AA $^{2}$

Submission: December 23, 2017 Published: January 18, 2018

"Corresponding author: SSh Shalataev, M Auezov South Kazakhstan State University, Kazakhstan, Russia, Email: zhantasov@mail.ru

\begin{abstract}
The article contains information about the existence in the world of a multitude of herbicide assortments with specific soil and crops with different names, with high activity; in particular glyphosate is a class of herbicides that makes a great contribution to protecting useful crops from weeds. It is given that in factories of the phosphoric sub-sector, phosphoric acid is phosphoric acid in the technological redistribution of phosphate-siliceous raw materials, and then a return is formed in ammophos leading to dustiness and gas contamination of the production room. In the production of phosphate-siliceous raw materials in ore-thermal furnaces of yellow phosphorus, in the condensation stage of phosphorus, a sludge containing up to $65 \%$ of elemental phosphorus, $25 \%$ of water and $10 \%$ of mineral substances is formed in the form of waste. For economic reasons, in order to avoid loss of phosphorus, and especially in sanitary conditions, studies were carried out to enrich phosphor sludge by cold washing with hydraulic classification and extraction of phosphorus from it, followed by the synthesis of glyphosate. It was found that a decrease in the rate of washing water leads to a decrease in losses of phosphorus with washed dirt and its enrichment by $10-15 \% \mathrm{P}_{4}$.
\end{abstract}

\section{Introduction}

In addition, an increase in the moisture content of the phosphorus-containing sludge for washing is accompanied, under the same conditions, by an increase in the specific water discharge. Dependences of phosphorus extraction from phosphorus sludge on temperature are shown, and it is also shown that an increase in temperature contributes to an increase in the yield of phosphorus. The analysis of the dry residue of the sludge carried out on the scanning electron microscope ISM 6390 LV (Japan) showed that the resulting dry residue can be attributed to the enriched superphosphate containing trace elements and used as a phosphorus fertilizer. Using phosphorus phosphorus sludge in the form of phosphorous and phosphoric acid and other organic compounds, studies have been carried out to obtain glyphosate in determining the possibility of chemical reactions and Gibbs energy.

A technological scheme for the production of herbicides was developed, while thermodynamic calculations were used to take into account empirical values available in the scientific literature widely used in engineering and technological work. Improving the welfare of the people of any state is constantly in the center of attention, since the growth and consumption of the products of the chemical and agrochemical industries depend on this indicator. One of the most important tasks of this topical program is the development of the material and technical base of the agro-industrial complex, encompassing the expansion of the production of plant protection products with high-performance properties, the agricultural sector of the economy, since in many cases the areas of sowing land are occupied by the sorino plants. In order to increase the yield of agricultural crops and improve the ecological situation in industrial regions that make it possible to secure the livelihoods of people and their fauna and flora, it is necessary to find new and improved methods for the utilization of industrial wastes with the production of chemical plant protection products based on pesticides. Pesticides or insecto-fungicides are chemical compounds of inorganic and organic substances used to control pests and diseases of cultivated plants. A significant number of nomenclatures of 
pesticides are produced from raw materials at chemical industry enterprises and only a small part with the use of waste products of non-ferrous metallurgy, pharmaceuticals, At the present stage, there are several ways to control pests and pathogens of plant diseases, of which the most effective and widespread is the chemical method, which involves the use of toxic substances for pests of agricultural crops.

The variety of pest species and diseases of cultivated plants causes the use of pesticides of different composition, which, depending on their effect on the insect organism and weeds, and the chemical composition are divided into several groups. For example, arsenic containing a compound used by agriculture is divided into two groups: arsenites in the form of trioxide $\mathrm{As}_{2} \mathrm{O}_{3}$ and arsenates containing five oxide $-\mathrm{As}_{2} \mathrm{O}_{5}$ [1-5]. The first group includes arsenites of calcium and sodium, Parisian greens, and the second group contains calcium arsenate. Of these substances, calcium and sodium arsenites are more soluble and more toxic than calcium arsenate [1-3]. Along with them, from the inorganic substances, we use sodium silicofluorides, barium salts such as barium chloride, barium carbonate, zinc phosphide [1-7]. In addition, there are a number of inorganic pesticides in the form of powders, granulated preparations, microcapsules, solutions, emulsions, aerosols, a mixture of preparations based on nitro compounds, amines and quaternary ammonium salts, hydrocarbons, halogenated coal Hydrogen, alcohols, phenols, ethers, carboxylic acids and their derivatives, as well as derivatives of carbonic acid, sulfides, urea and thiourea, thiols, thiocyanates, sulfonic acids and derivatives of the aforementioned substances, derivatives of hydrazine, sulfuric and sulfuric acids, azo compounds, mercury, tin, silicon, lead, germanium, phosphorus, arsenic, antimony, iron, boron, organophosphate pesticides based on insecticides, fungicides, herbicides and plant regulators, including a large assortment of phosphorus Form containing preparations based on phosphonomethylglycine and its derivatives, (salts, esters, nitrides, derivatives of the carboxyl and phosphonic group) of phosphinotricyl and its derivatives, glyphosate, cranate, phosphorus-containing amino acids and others.

The history of the application of chemical methods for controlling plant diseases begins in 1882, when the French naturalist Pierre Millarde discovered the Bordeaux fluid, which until now has not lost its significance. In history, there are even earlier evidence of the use of various substances for plant protection. Based on the analysis of the above scientific work, one of the promising pesticides is glyphosate, a broad-spectrum preparation [6-17]. The growth rate of the chemical industry exceeds the growth rates of world GDP and the increase in production in the chemical industry by 1 conventional unit (in US dollars), the increase in production in other sectors of the economy, according to CEFIC (2014), including petrochemicals, is up to 2.1US Dollars [10]. The Republic of Kazakhstan is the owner of a resource of raw materials and materials of great importance in various industrial sectors of the economy, where out of 105 chemical elements of the table, D.I. Mendeleyev 99 elements are used in the production of various products. Mass development of pests or diseases of living organisms causes the need to control them with the help of pesticides.

The most common way in the world to control pests and diseases of wildlife and material, as mentioned above, is the chemical method. It is very difficult to cope with pests of agricultural crops on large areas without pesticides and, according to scientists; the increase in yield from chemical plant protection is from 20 to $60 \%$. For example, the yield increase in Europe only from chemical plant protection ranges from 40 to $60 \%$ [11]. Therefore, non-use of chemicals can lead to huge losses of food. The properties of more than 35 thousand compounds of pesticides have been obtained and tested, the release of which around the world amounts to about 5 thousand titles. In Russia, this list is much shorter, and includes about 200 drugs [14]. Among the above mentioned preparations, glyphosate is the most popular and widespread in the world agrochemical product based on phosphorogenic substances, which can migrate through the vascular system of weeds, destroying not only the terrestrial, but also the underground root part of plants. For the first time, herbicidal properties of glyphosate were discovered in the United States by John Franz by a Monsanto employee in 1970 and a national medal in 1987. The expiration in 2000 of Monsanto's patent for the glyphosate molecule led to the emergence of competitors in the market, producing analogues of the product of the trade mark Roundup.

At present, there are dozens of glyphosate brands on the market under various names: Thunderbolt, Gladiator, Glyphos Super, Touchdin, Chistopol, Vulcan, Smersh, Roundup and Uragan. The potassium salts of glyphosate, for example "Uragan Forte", the product of the company "Syngenta", which contains $44.7 \%$ of potassium glyphosate and up to $20 \%$ of substituted amines and hydrocarbons, also have high activity. In world agriculture, despite the fact that glyphosate represents a class of herbicides and is a generic, it makes the greatest contribution to the protection of useful crops. Many crops are genetically engineered to be resistant to glyphosate $[18,19]$. One of the main and widely used herbicides is glyphosate, which is derived from organophosphorus compounds whose chemical formula is $\mathrm{C}_{3} \mathrm{H}_{8} \mathrm{NO}_{5} \mathrm{P}$ or the organophosphorus compound [ $\mathrm{N}$ (phosphonomethyl) glycine]. These are well water-soluble granules or white crystals that do not have a smell. They are very difficult to dissolve in organic solvents, but with organic bases form salts that are highly soluble in water. From a chemical point of view, glyphosate is a weak organic acid.

In order to increase the solubility in the formulation, glyphosate is converted to potassium, ethanolamine, dimethylamine, ammonium or isopropylamine salt consistency. As an active ingredient, most herbicidal preparations based on glyphosate contain the isopropylamine salt. Abroad, glyphosate is also used in the preparation of tank mixtures with alachlor, 
atrazine and simazine, dinuron, metribusin, etc. Compositions containing various herbicides are needed in agriculture and other areas to expand the spectrum or range of species of plants to be destroyed with which to fight. In view of the need for compositions with the aforementioned properties, a combination of a triazolinone herbicide and a glyphosate salt is disclosed, for example, in US patents [17-25]. The authors of these studies suggest that the combination of the triazolinone herbicide and the glyphosate salt have a herbicidal effect against a very wide range of weed plants. Typically, glyphosate as a salt has a sufficiently high solubility in water to produce a highly concentrated herbicidal preparation. For example, the US patent shows an isopropylamine salt (IPA) and a monoethanolamine (MEA) glyphosate salt [18].

US Patents show various preparations that include potassium (P) glyphosate salt and are preferred for various economic and environmental reasons, reducing the cost of shipping, preparing and the quantities of packaging material requiring recycling $[19,20]$. As in plants for the production of mineral fertilizers in the production of ammophos a significant amount of fine dispersed ration is formed, which worsens the ecological situation in the production premises. In addition, with the technological redistribution of phosphate-siliceous raw materials in ore-thermal furnaces, the second waste generated in the phosphorus condensation step is a sludge containing phosphorus and a mineral residue from inorganic substances. As accumulation and long storage, phosphorus slurries "age", reducing the output of elemental phosphorus when they are processed into target products.

In all the studies analyzed, no information was provided on the production of glyphosate using waste from the phosphate sub-sector. Therefore, the aim of the research was to improve the technology of glyphosate production by introducing into the technological process a retort of ammophos and phosphorus sludge, the production costs of mineral fertilizers and elemental yellow phosphorus, depending on the type of natural phosphates subjected to electrothermal processing for yellow phosphorus. To carry out qualitative and quantitative analyzes of liquid-phase and solid-phase samples, which are selected at different stages of experimental research, the content of certain elements and compounds, conventional standard methods and modern instruments and equipment for physical and chemical studies were used. In order to intensify the process of obtaining glyphosate and reduce the number of commodity reaction products, studies have been carried out on the partial replacement of ammonia and phosphorus, in the form of phosphorous acid from ammophos, the thermographic analysis of which is shown in Figure 1.

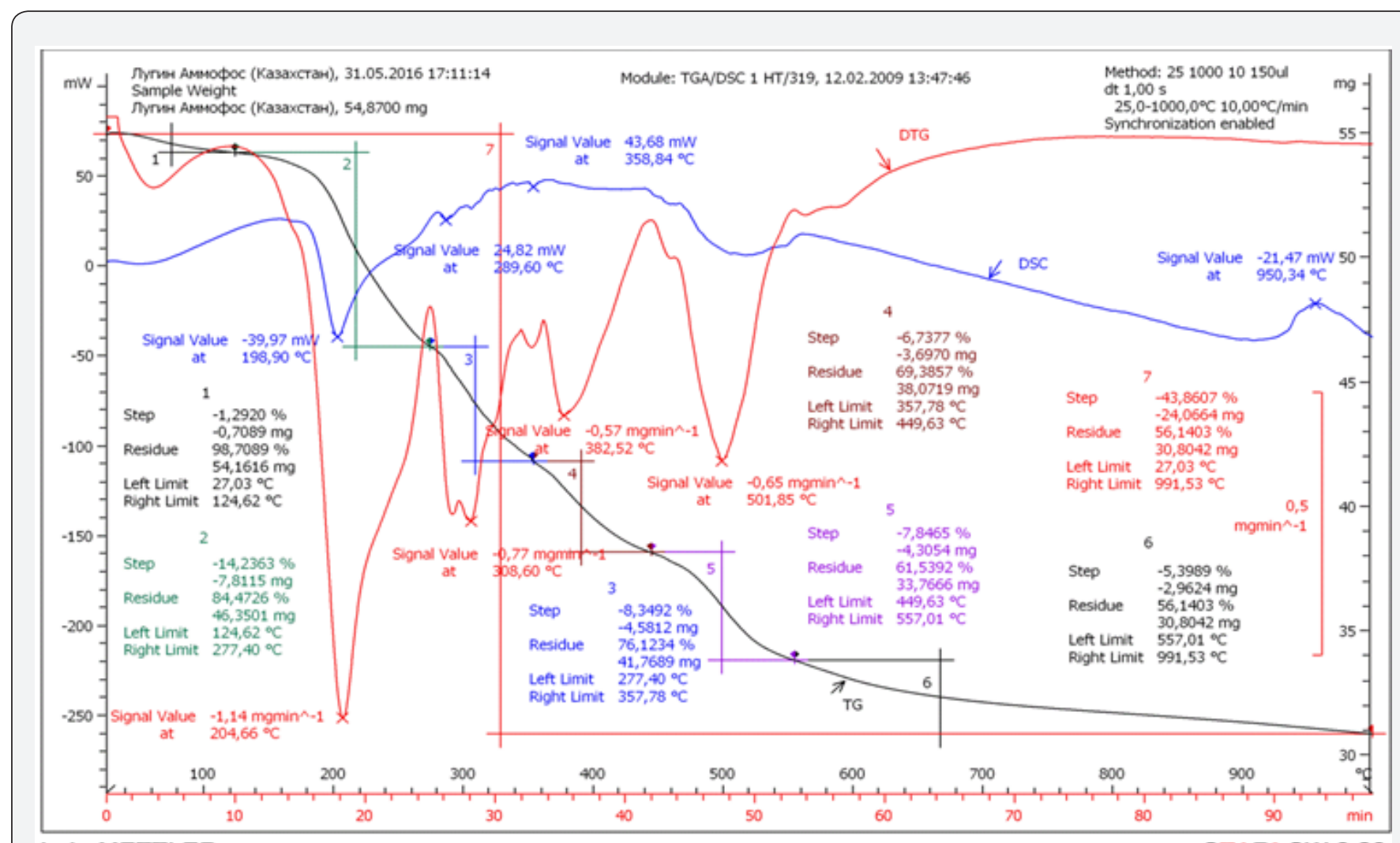

Lab: METTLER

STAR $^{\circ}$ SW 9.20

Figure 1: Thermogram of the ammophos retort. 
On the basis of experimental studies and the results obtained, it should be noted that the process of obtaining three alkyl sulfate salts of $\mathrm{N}$-phosphonomethylglycine is characterized by the following main stages:

Step 1: Preparation of intermediate bis-phosphonomethyl 2,5-diketopiperazine using a low molecular carboxylic acid based on acetic, propionic and butanoic acids;

Stage 2: separation of bis-phosphonomethyl 2,5-diketopiperazine intermediates during heating;

Stage 3: interaction of bis-phosphonomethyl 2,5-diketopiperazine compound with hydrolysis with distilled water and dilution of sodium alkali in it;
Stage 4: Acidification of the obtained salt with hydrochloric acid to form the final product of N-phosphonomethylglycine. The ratio of 2,5-diketopiperazine: $n$-formaldehyde: phosphorus trichloride during the study was $1: 1.5: 1.5$.

To improve the environmental and technical and economic indicators of production of ammophos and glyphosate, studies have been carried out to intensify the technology through the use of the ammophos retort.

The IR spectroscopic analysis of ammophos from the phosphatites of the Zhanatas deposit, shown in Figure 2, shows that it mainly contains ammonium dihydrogen phosphate, t. in the IR spectrum of ammophos all the most intense absorption bands correspond to the absorption bands of ammonium dihydrogen phosphate.

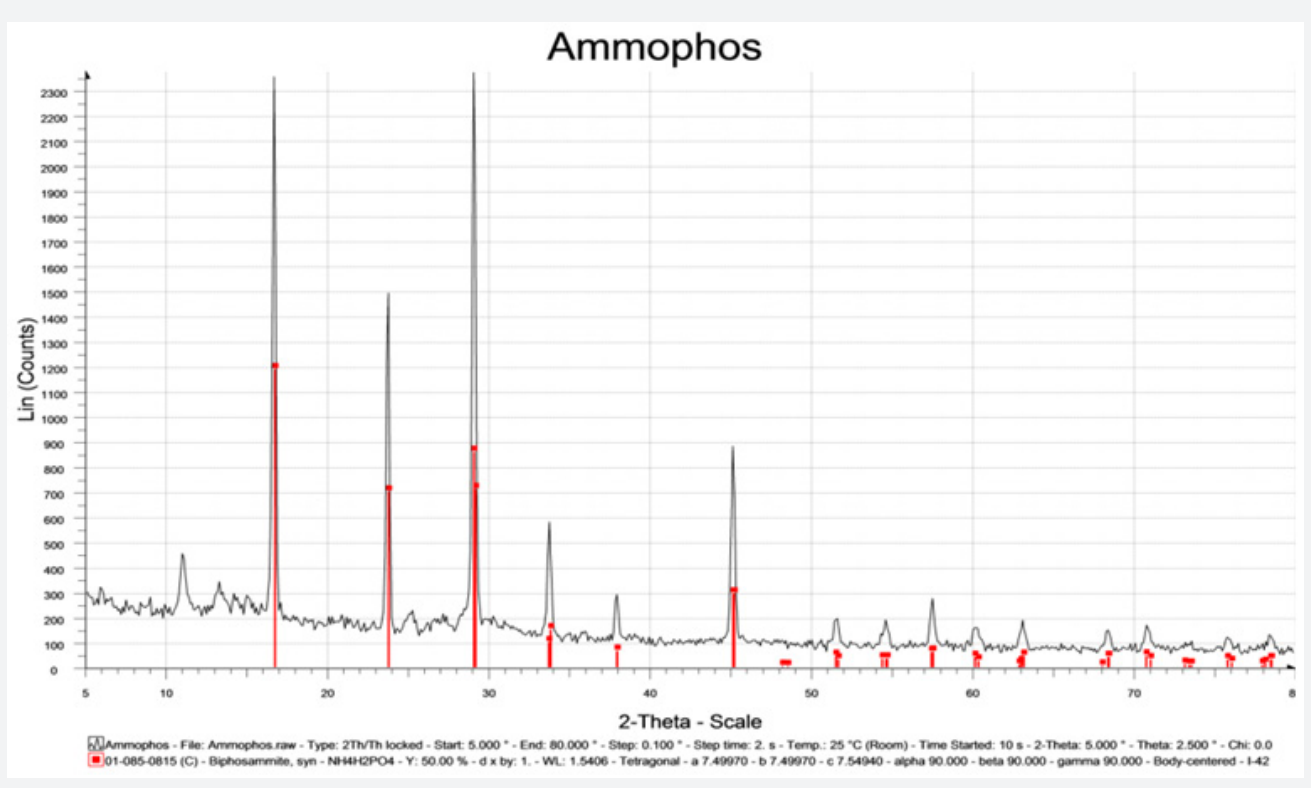

Figure 2: X-ray phase analysis of the ammophos retort.

According to the data of TGA and DSC thermograms, it was established that the thermal decomposition of ammophos proceeds in 6 stages. The first stage - in the temperature range $27-125^{\circ} \mathrm{C}$ with a loss of $1.29 \%$ of the mass; The second - in the temperature range of $125-277^{\circ} \mathrm{C}$, where the maximum mass loss rate of $14.24 \%$ is - at a temperature of $205^{\circ} \mathrm{C}$; The third stage is in the range $277-358^{\circ} \mathrm{C}$; at a maximum of the decomposition rate at this stage of $8.35 \%$ at a temperature of $309^{\circ} \mathrm{C}$; The fourth stage is $358-450^{\circ} \mathrm{C}$; at which the maximum decomposition rate of $6.74 \%$ is at $382^{\circ} \mathrm{C}$; The 5 th stage is $450-557^{\circ} \mathrm{C}$; at which the maximum decomposition rate of $7.85 \%$ is at $502^{\circ} \mathrm{C}$; 6 th stage at $557-991^{\circ} \mathrm{C}$; with a mass loss of $5.4 \%$.

At the first stage, adsorbed water is removed. In the temperature range corresponding to the second stage (125$277 \mathrm{oC}$ ), a large mass loss is observed, which is intense before and after the melting of ammonium dihydrogen phosphate (t.pl. $=1990 \mathrm{C}$, according to the minimum on the DSC curve).
In this temperature range, the process of deammonization and dehydration of ammonium dihydrogen phosphate begins, which is accompanied by the polymerization of dihydroorthophosphate ions with the formation of diphosphate, triphosphate and tetra phosphate anions. In the third and fourth stages of thermal decomposition of ammophos, the polycondensation process proceeds more deeply in the temperature range $300-440^{\circ} \mathrm{C}$, resulting in the formation of phosphate anions with an average chain length of more than 7. At temperatures above $450^{\circ} \mathrm{C}$ (the fifth stage), decomposition of polycondensation products begins, which is accompanied by a greater loss of mass than in the previous stage. At the same time, a small endothermic effect is observed on the DSC curve. The total loss of mass upon calcinations of ammophos to $1000^{\circ} \mathrm{C}$ is $43.86 \%$, which is higher than the calculated (39.05\%) for a mixture of dihydrogen phosphate (90 mass \%) and hydro phosphate (10 mass\%) characterizing the approximate composition of ammophos. This may be due to the sublimation of phosphorus oxide, the product 
of complete decomposition of ammonium phosphates, at a temperature above $600^{\circ} \mathrm{C}$ and the release of a significant amount of ammonia.

Analysis of the morphological and chemical composition (Figures 3-5) obtained on a scanning microscope JSM 6390 LV (Japan) shows that the content of phosphorus in the product under study is 35 to $42 \%$, impurities in it are iron, magnesium, calcium, aluminum, potassium, sodium, manganese and silicon. In connection with the fact that the process of thermal decomposition of ammophos proceeds at temperatures above 900oC, with the formation of hardly soluble pyrophosphoric acid into phosphorous acid, further investigations were carried out on phosphorus sludge, which showed positive results. At phosphorus plants, with the technological redistribution of phosphate-siliceous raw materials in ore-thermal furnaces, in the condensation stage of phosphorus, a sludge containing up to $65 \%$ of elemental phosphorus, $25 \%$ of water and $10 \%$ of mineral substances, on the average, is formed for economic and environmental reasons. Avoid loss of phosphorus and especially on sanitary conditions to throw out their categorical are not permissible, in connection with which, as they accumulate, they are recycled.
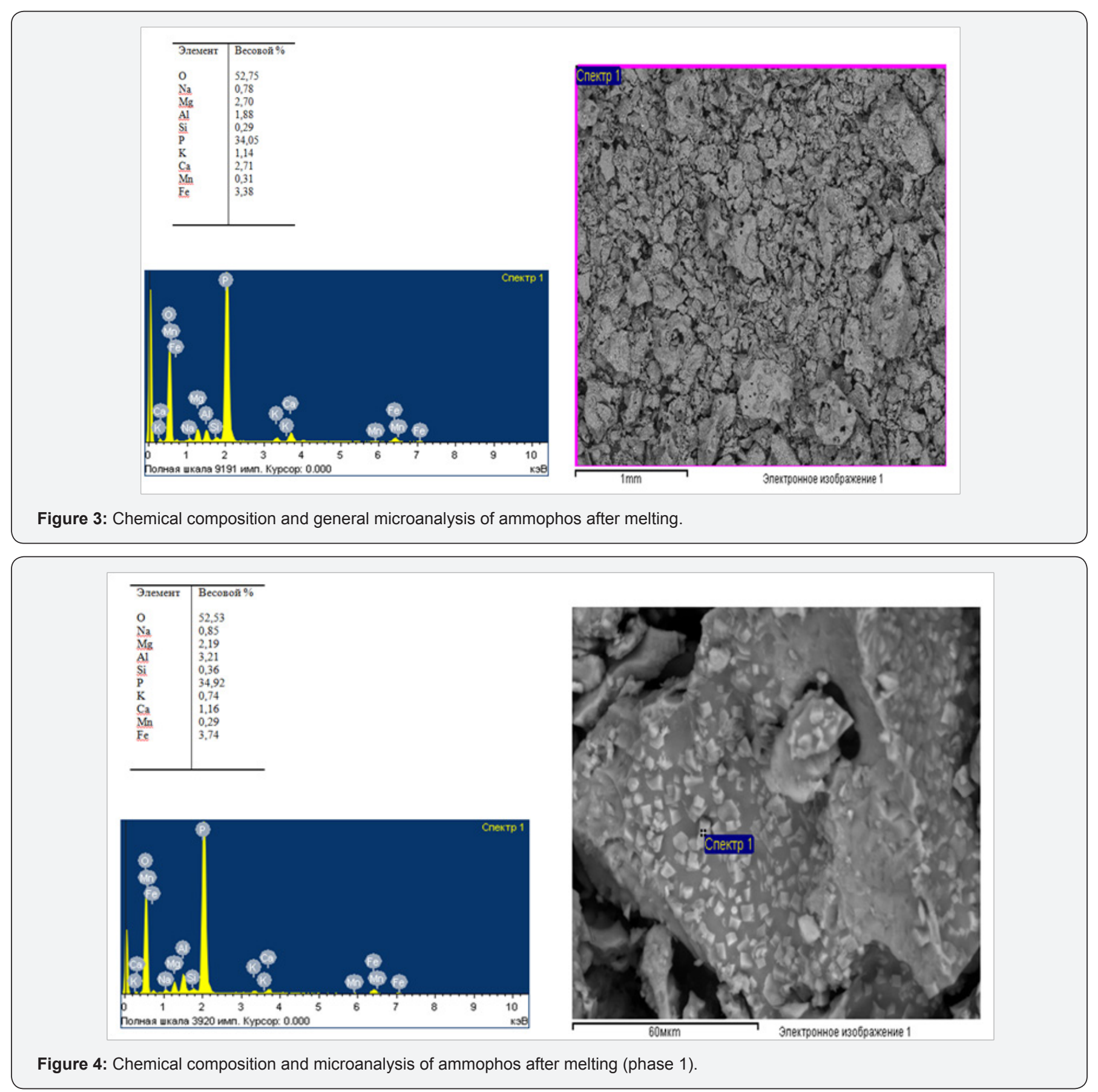


\begin{tabular}{l|l}
\hline Элементт & Beconoñ \% \\
$\mathrm{O}$ & 43.95 \\
$\mathrm{Na}$ & 0.44 \\
$\mathrm{Mg}$ & 2.15 \\
$\mathrm{Ml}$ & 0.37 \\
$\mathrm{Al}$ & 0.14 \\
$\mathrm{Si}$ & 42.14 \\
$\mathrm{P}$ & 2.35 \\
$\mathrm{~K}$ & 6.74 \\
$\mathrm{Ca}$ & 0.36 \\
$\mathrm{Mn}$ & 0.36 \\
$\mathrm{Fe}$ & \\
& \\
\hline
\end{tabular}
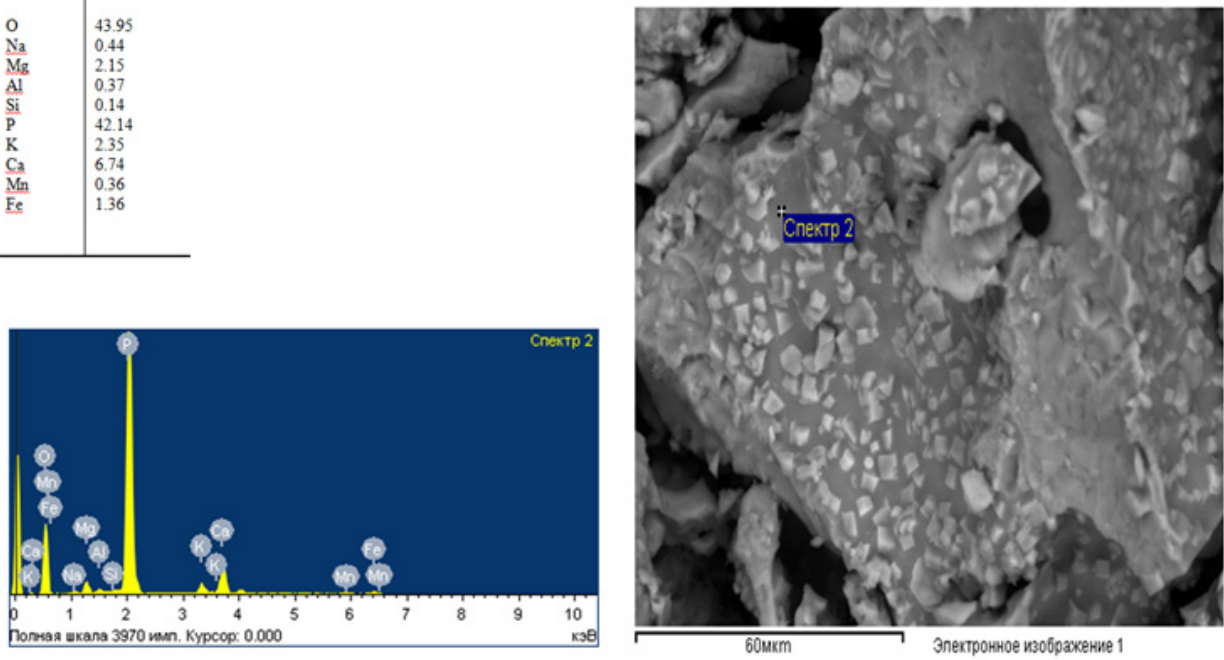

Inca

Figure 5: Chemical composition and microanalysis of ammophos after melting (phase 2).

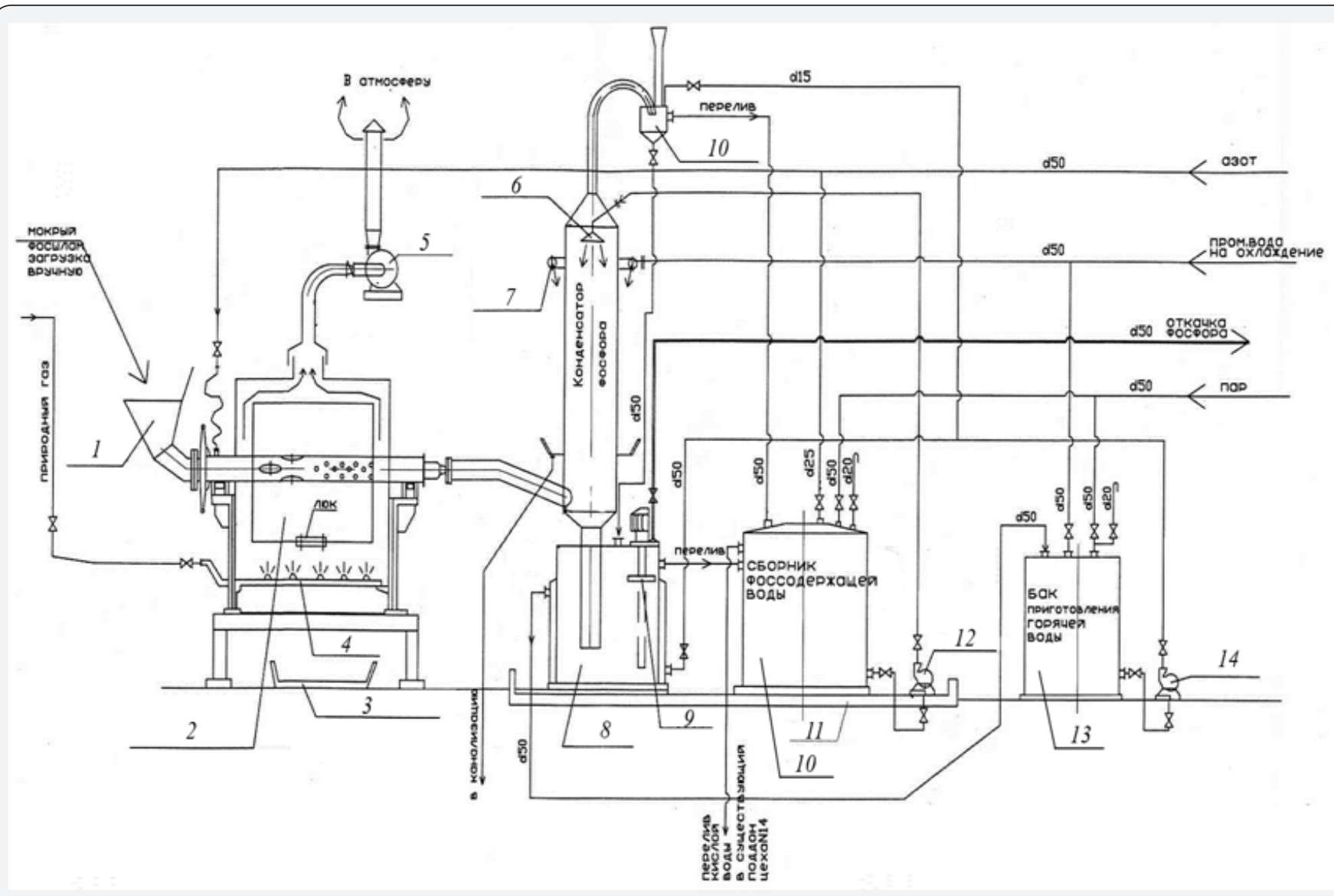

1- funnel with hinged lid; 2-device for sublimation of sludge; 3-trough for removal of dry sludge residues; 4-burner; 5-exhaust fan; 6-injector; 7-collector irrigation of cooling water; 8-collection of phosphorus with a jacket; 9-pump; 10-hydraulic shutter; 11-pallet; 12-ts.b. pump; 13tank hot water preparation; 14-cent.b. pump.

Figure 6: Technological scheme of hydraulic classification of phosphorus from phosphorus sludge. 


\section{Organic and Medicinal Chemistry International Journal}

Based on the information given earlier, studies were carried out on the enrichment of phosphorus sludge by cold washing with hydraulic classification and extraction of phosphorus from it in the pilot plant shown in Figure 6. Creation of certain conditions under hydraulic classification, i.e. speeds, will increase the concentration of phosphorus in the sludge, and then from this phosphorus to obtain phosphoric and phosphorous acids. To wash the poor phosphorus sludge used in the studies, a pressure vessel with a capacity of 10 liters was used, and equipped with a crane, long hoppers of capacity 0, 6 and 1 liter, connecting hoses other devices. Sludge washing was carried out for the purpose of calculating and drawing up a material balance without straining the original sludge. During the washing of the mineral part, hard pieces of irregular shape with a size from 1 to $10 \mathrm{~mm}$ were found (Table 1).

Table 1: The content of products at different washes washing speed.

\begin{tabular}{|c|c|c|}
\hline \multirow{2}{*}{ Name } & \multicolumn{2}{c|}{ Speed in sm/sec } \\
\cline { 2 - 3 } & $\mathbf{0 , 0 0 1}$ & $\mathbf{0 , 0 1}$ \\
\hline a) The volume of washing water in liters & 2 & 2 \\
\hline b) Concentration of P4 in\% in the original sludge & 20,3 & 20,3 \\
\hline c) Concentration of P4 in\% in the funnel & 24,8 & 25,16 \\
\hline d) Concentration of P4 in\% in washed mud & 4,23 & 4,23 \\
\hline e) Sludge volume & 250 & 250 \\
\hline
\end{tabular}

Table 2.

\begin{tabular}{|c|c|c|c|c|c|c|c|}
\hline \multirow{2}{*}{ No } & \multicolumn{7}{|c|}{ Element composition of glyphosate in \% } \\
\cline { 2 - 8 } & $\mathbf{C}$ & $\mathbf{N}$ & $\mathbf{0}$ & $\mathbf{P}$ & $\mathbf{S}$ & $\mathbf{C I}$ & $\mathbf{N a}$ \\
\hline 1 & 28,1 & 14,74 & 40,81 & 13,85 & 0,64 & 1,65 & - \\
\hline 2 & 27,89 & 14,62 & 40,86 & 14,29 & 0,65 & 1,69 & - \\
\hline 3 & 28,92 & 14,25 & 40,13 & 14,04 & 0,61 & 1,81 & 0,24 \\
\hline 4 & 28,97 & 14,46 & 40,75 & 14,29 & 0,56 & 1,69 & 0,15 \\
\hline
\end{tabular}

Analysis of the data in Table 2 shows that:

A. Reduction of the washing water rate (less than $0.02 \mathrm{~cm}$ / s) leads to a decrease in losses of phosphorus with washed dirt and its enrichment from 20 to $30-35 \% \mathrm{P}_{4}$;

B. an increase in the volume of phosphorus-containing sludge for washing is accompanied, under the same conditions, by an increase in the specific water discharge.

The extraction of phosphorus from phosphorus sludge as a function of temperature is shown in Figure 7, which shows that an increase in temperature contributes to an increase in the yield of phosphorus from phosphorus-containing sludge to $84 \%$. The data of the analysis of the average chemical composition of the products - phosphor sludge, slag and phosphorus are given in Table 3. The analysis of the dry residue of the sludge carried out on the scanning electron microscope ISM $6390 \mathrm{LV}$ (Japan) and presented in Figure 8 shows that it contains (in\%) about 23 or more phosphorus; iron - 1,8; zinc - 1.03; magnesium - 0.1 ; silicon - 1,2; calcium - 1,3; potassium - 0.1; aluminum - 0.3 and sodium 0.35 . Based on this, it can be concluded that it can be attributed to enriched superphosphate containing trace elements and are recommended for use as a phosphorus fertilizer.

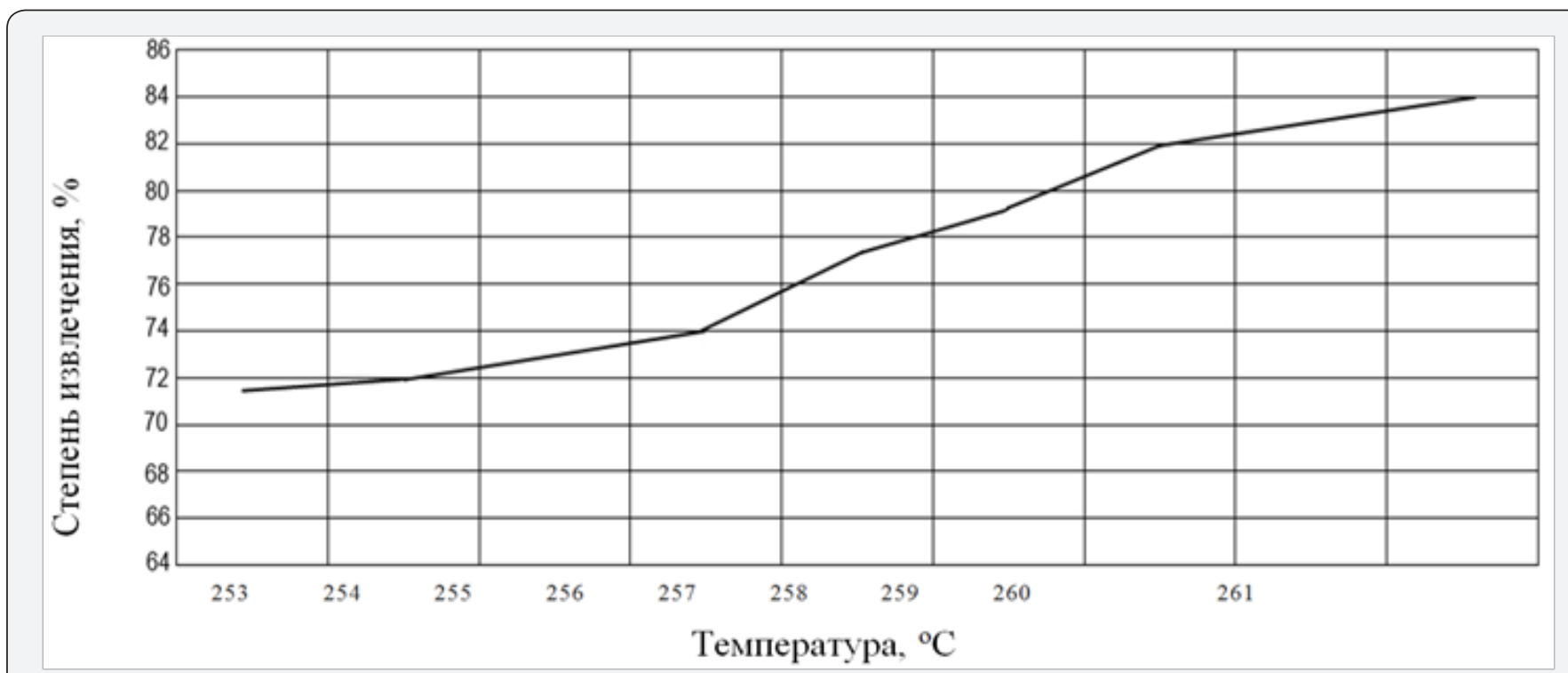

Figure 7: Dependence of the degree of extraction of phosphorus from the sludge on the temperature. 
Table 3: Average chemical composition of products.

\begin{tabular}{|c|c|c|c|c|c|c|c|}
\hline \multirow{2}{*}{ Name } & \multicolumn{7}{|c|}{ Content of components in $\mathbf{\%}^{\prime}$} \\
\cline { 2 - 8 } & $\mathbf{S i O}_{2}$ & $\mathbf{P}_{\mathbf{2}} \mathbf{O}_{\mathbf{5}}$ & $\mathbf{C a O}$ & $\mathbf{A l}_{\mathbf{2}} \mathbf{O}_{\mathbf{3}}$ & $\mathbf{F e}_{\mathbf{2}} \mathbf{O}_{\mathbf{3}}$ & $\mathbf{F}$ & $\mathbf{P}_{4}$ \\
\hline Sludge & 42,2 & 18,5 & 16,8 & 2,6 & 2,3 & 0,94 & 12,6 \\
\hline Slag & 18,5 & 18,9 & 9,9 & 1,7 & 1,3 & 3,2 & 6 \\
\hline Phosphorus & 0,4 & - & - & - & - & - & 99,6 \\
\hline
\end{tabular}
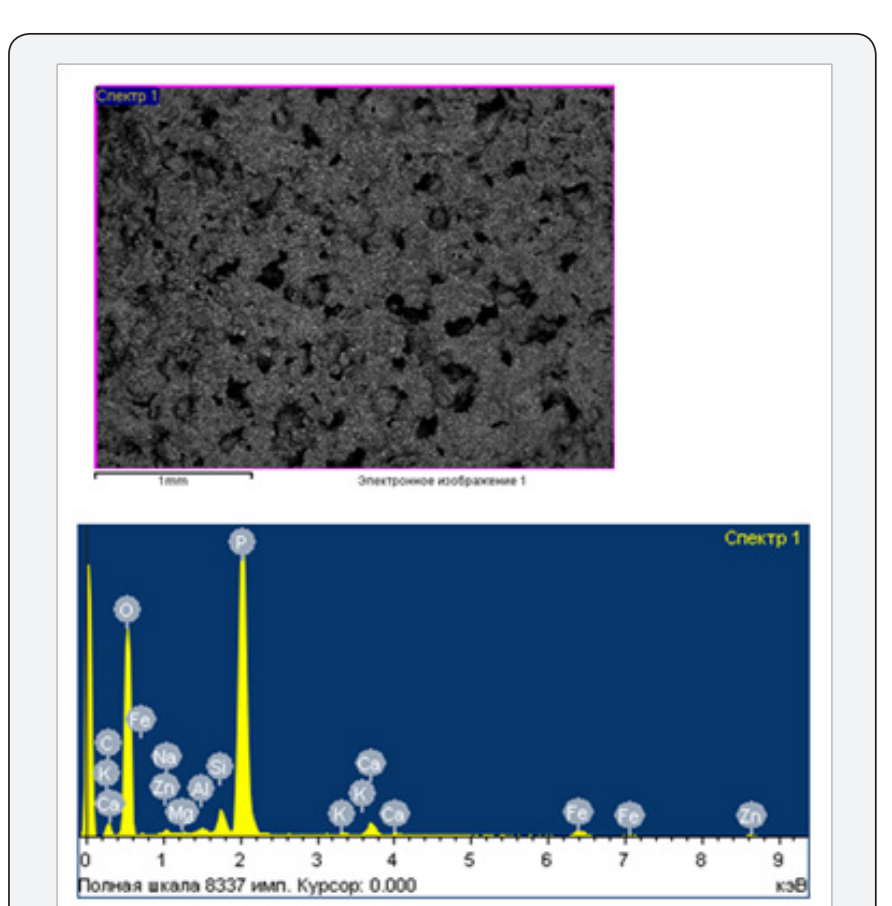

Figure 8: Spectral analysis of the dry residue of phosphorus sludge.

When phosphorus sludge was processed to elemental phosphorus, and then to phosphoric acids, the product settled in phosphorus assemblies of the towers of "hot" and "cold" condensation was used as sludge, formed during processing of agglomerate from fines of phosphorites in the Karatau basin of the current supply. To determine, as well as to identify the thermal effects of the possibility of the thermochemical reaction of obtaining intermediates and glyphosate from the raw materials, reference data of physicochemical substances are used in the calculations. The consumption of raw materials and energy costs was based on the thermodynamic calculation of the possibility of reactions at the first and second stages, with the identification of Gibbs energy, which is given below. The organic components were calculated taking into account not only the chemical but also the structural formula of the substances participating in the reaction interaction. Data on the calculation of the possibility of reactions 1 and 2 of inorganic and organic substances are given in Tables 4 \& 5 using reference data and empirical assumptions with chemical and structural gross formulas.

$\left(\mathrm{CH}_{2}-\mathrm{CH}_{2} \mathrm{OH}\right)_{2} \mathrm{NH}+\mathrm{H}_{3} \mathrm{PO}_{3}+1,5 \mathrm{O}_{2} \rightarrow\left(\mathrm{CH}_{3} \mathrm{COCH}_{3}\right)_{2} \mathrm{NH}+\mathrm{H}_{3} \mathrm{PO}_{4}+\mathrm{CO}_{2} \ldots . . .(1)$

$\left(\mathrm{CH}_{3} \mathrm{COCH}_{3}\right)_{2} \mathrm{NH}+\mathrm{H}_{3} \mathrm{PO}_{4}+\mathrm{NaOH}+4, \quad 5 \mathrm{O}_{2} \rightarrow \mathrm{C}_{3} \mathrm{H}_{8} \mathrm{NO}_{3} \mathrm{P} \downarrow+3 \mathrm{CO}_{2} \uparrow+4 \mathrm{H}_{2} \mathrm{O}+\mathrm{NaOH}$ ......(2)
Table 4: Calculation of the possibility of the occurrence of reactions 1 and the determination of Gibbs energy.

\begin{tabular}{|c|c|c|c|}
\hline Substance & $\begin{array}{c}\Delta \mathrm{H}_{\mathrm{f}}{ }^{0}, 298 \\
\mathrm{~kJ} / \mathrm{mole} . \mathrm{K}\end{array}$ & $\underset{298}{S_{20}, \mathrm{~J} / \mathrm{mole}}$ & $\begin{array}{c}\mathrm{C}_{\mathrm{p}}{ }^{0}, 298 \mathrm{~J} / \\
\text { mole. K }\end{array}$ \\
\hline $\begin{array}{c}\left(\mathrm{CH}_{3} \mathrm{COCH}_{3}\right)_{2} \mathrm{NH} \\
\text { iminodiacetonitrile }\end{array}$ & $-4434,28$ & 2090,9 & 354,97 \\
\hline $\mathrm{H}_{3} \mathrm{PO}_{4}$ & $-1279,3$ & 110,5 & 106,1 \\
\hline $\mathrm{CO}_{2}$ & $-393,51$ & 213,6 & 37,13 \\
\hline$\sum$ final products & $-6107,09$ & 2415,0 & 498,2 \\
\hline $\begin{array}{c}\left(\mathrm{CH}_{2}-\mathrm{CH}_{2} \mathrm{OH}\right)_{2} \mathrm{NH} \\
\text { diethanolamine }\end{array}$ & $-3251,47$ & 1740,32 & 294,97 \\
\hline $\mathrm{H}_{3} \mathrm{PO}_{3}$ & $-952,8$ & 45,43 & 158,56 \\
\hline $1,50_{2}$ & 0 & 307,55 & 40,04 \\
\hline$\sum$ initial products & $-4204,27$ & 2093,3 & 497,57 \\
\hline$\Delta$ reactions & $-1902,82$ & 321,7 & 0,63 \\
\hline
\end{tabular}

Table 5: Calculation of the possibility of reactions 2 and the determination of Gibbs energy.

\begin{tabular}{|c|c|c|c|}
\hline Substance & $\begin{array}{c}\Delta \mathrm{H}_{\mathrm{f}}^{\mathrm{o}}, 298 \mathrm{~kJ} / \\
\text { mole. } \mathrm{K}\end{array}$ & $S_{298}{ }^{0}, J /$ mole. K & $\begin{array}{c}\mathrm{C}_{\mathrm{p}}{ }^{0}, 298 \mathrm{~J} / \\
\text { mole. K }\end{array}$ \\
\hline $\begin{array}{l}\mathrm{C}_{3} \mathrm{H}_{8} \mathrm{NO}_{3} \mathrm{P} \\
\text { glyphosate }\end{array}$ & $-4675,74$ & 196,983 & 333,87 \\
\hline $3 \mathrm{CO}_{2}$ & $-1180,53$ & 640,3 & 111,39 \\
\hline $4 \mathrm{H}_{2} \mathrm{O}$ & $-11,43,36$ & 279,84 & 301,24 \\
\hline $\mathrm{NaOH}$ & $-426,6$ & 64,18 & 59,66 \\
\hline$\sum$ final products & $-7426,23$ & 2954,15 & 806,16 \\
\hline$\left(\mathrm{CH}_{3} \mathrm{COCH}_{3}\right)_{2} \mathrm{NH}$ & $-4434,28$ & 2090,9 & 354,39 \\
\hline $\mathrm{H}_{3} \mathrm{PO}_{4}$ & $-1271,94$ & 200,83 & 106,1 \\
\hline $\mathrm{NaOH}$ & $-426,6$ & 64,18 & 59,66 \\
\hline $4,5 \mathrm{O}_{2}$ & 0 & 922,64 & 132,12 \\
\hline $\begin{array}{l}\sum \text { initial } \\
\text { products }\end{array}$ & $-6132,82$ & 3278,55 & 652,27 \\
\hline$\Delta$ reactions & $-1293,41$ & $-323,9$ & 153,89 \\
\hline
\end{tabular}

Based on the results presented, it follows that reactions 1 and 2 in the temperature range $298 \div 363 \mathrm{~K}$ are exothermic, therefore their thermodynamic flow is possible, and for inorganic components the calculation is made in the temperature range from 298 to 1073 Kelvin, the Gibbs energy has the values given below

$$
\begin{aligned}
& \Delta \mathrm{G}_{673}=-1838,56-321,69 \times 400=-130514,56 \mathrm{~kJ} / \mathrm{mole} \\
& \Delta \mathrm{G}_{873}=-1712,56-321,69 \times 600=-194726,56 \mathrm{~kJ} / \mathrm{mole} \\
& \Delta \mathrm{G}_{1073}=-1586,56-321,69 \times 800=-258938,56 \mathrm{~kJ} / \mathrm{mole}
\end{aligned}
$$

Reaction 
$\left(\mathrm{CH}_{3} \mathrm{COCH}_{3}\right)_{2} \mathrm{NH}+\mathrm{H}_{3} \mathrm{PO}_{4}+\mathrm{NaOH}+4,50_{2} \rightarrow \mathrm{C}_{3} \mathrm{H}_{8} \mathrm{NO}_{5} \mathrm{P}+3 \mathrm{CO}_{2}+4 \mathrm{H}_{2} \mathrm{O}+\mathrm{NaOH}$

$\Delta \mathrm{H}_{298}=1293,41 \mathrm{~kJ} / \mathrm{mole} . \mathrm{K}$

$\Delta \mathrm{cp}=153,89 \mathrm{~J} /$ моль.К

The introduction of thermal energy from the outside is necessary to maintain the temperature in the reaction zone, by using a heat agent in the reactor shirts.

Studies to obtain glyphosate were carried out in two stages:
In the first stage, phosphorous and phosphoric acids were obtained from phosphorus and phosphoric acids by combustion of phosphorus in a combustion plant at low temperature oxidation with dry air oxygen in the temperature range 200$320^{\circ} \mathrm{C}$, optimal $250-260^{\circ} \mathrm{C}$, and phosphorous anhydrite was obtained in the form of a white flocculent material. The resulting phosphorus trioxide powder was dissolved in water to form the acid by reaction

$$
\mathrm{P}_{4} \mathrm{O}_{6}+\mathrm{H}_{2} \mathrm{O}=4 \mathrm{H}_{3} \mathrm{PO}_{3}
$$

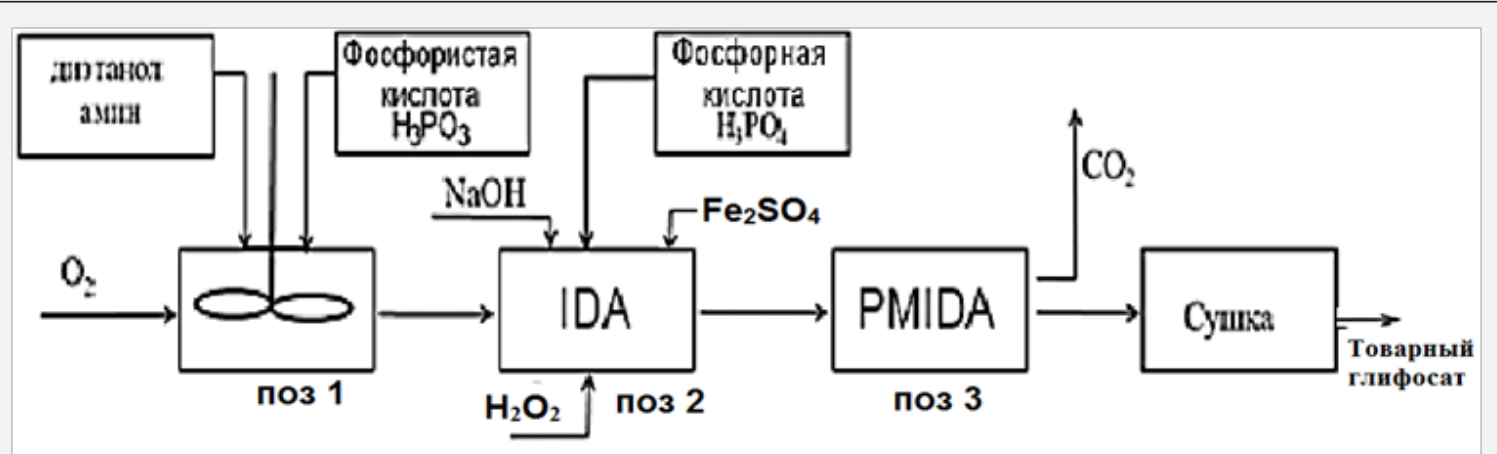

Figure 9: Schematic diagram of obtaining glyphosate.

Then, the acids obtained were used in the synthesis of glyphosate in reactors equipped with stirring devices and shirts to maintain the temperature with hot water in the reaction zone according to the flow diagram shown in Figure 9. According to the proposed technology, diethanolamine and phosphorous acid, obtained from phosphorus of phosphorus sludge, are used as starting materials for the synthesis of the sodium salt of imodiacitonitrile (IDA), in the first stage. In the second stage of the process, where sodium sulphate and iron sulfate are used as catalysts, and hydrogen peroxide is used as a reagent for the oxidation-reduction process.

After mixing, imodiacitonitrile (IDA) is synthesized, which is exposed to phosphoric acid, in the second stage, also obtained from phosphorus phosphorus sludge.

According to the developed technological scheme shown in Figure 9, diethanolamine and formaldehyde were supplied in certain ratios to the reactor pos. 1 , where the temperature was maintained in the range of $60-80^{\circ} \mathrm{C}$, in order to reduce the viscosity of the reagents used and increase their reactivity. Then to the reactor pos. 1, a phosphorous acid derived from phosphorus contained in the phosphorus sludge is introduced and mixed until a homogeneous mixture is obtained, in the presence of hydrochloric acid. From the reactor poses. 1, the resulting iminodiacetonitrile is poured into the enameled reactor pos. 2 where phosphoric acid, also obtained from phosphorus sludge, is fed. In the reactor pos. 2, sodium alkali and ferrous sulphate serve as a catalyst to accelerate the reaction. Iminodiacetonitrile, reacting with an aqueous solution of sodium hydroxide, hydrochloric acid and formaldehyde passes into PMIDA - phosphomethyliminodiacetonitrile.
Subsequently, hydrogen peroxide is also fed to the reactor for positioning the oxidation-reduction reaction in order to convert iminodiacetonitrile in the presence of formaldehyde to phosphonomethyl-iminodiacetonitrile. Ammonia gas, carbon dioxide, water, sodium chloride and glyphosate obtained by purging ammonia gas through it are concentrated, fixed and the resulting white flocculent precipitate is obtained, after drying at $150-200^{\circ} \mathrm{C}$, white crystalline glyphosate passes. The preparation of glyphosate can be represented as the above reactions 1 in the first stage and in the second stage of the reaction 2 . The glyphosate synthesis process, with the formation of a strictly desired product, can be represented as the following summarized reaction:

The resulting precipitate of phosphonomethylated amino acids is reduced to glyphosate by oxidation using hydrogen peroxide. Iminodiacetonitrile reacts with an aqueous solution of sodium hydroxide and hydrochloric acid to form ammonia and sodium iminodiacetate, which reacts with an aqueous solution of phosphorus trichloride and formaldehyde into phosphomethyliminoimidiacetonitrile (PMIDA). The product is concentrated, subjected to membrane separation to form a 10$20 \%$ aqueous solution of glyphosate, and treated with ammonia gas, with further production of ammonium glyphosate. During the course of the above total reaction, ammonia, water and sodium chloride are formed. According to traditional technology, phosphorus trichloride is necessary for the production of $\mathrm{H}_{3} \mathrm{PO}_{3}$-phosphorous acid used in the PMIDA synthesis step in the presence of formaldehyde, which is also formed during the oxidation-reduction of PMIDA by hydrogen peroxide in the presence of sodium tungstate and ferrous sulphate, shifting the 
reaction to the right side of the chemical equilibrium. Therefore, in industrial conditions, this stage can be eliminated by the use of phosphorous acid.

Phosphorus pentaoxide is produced by burning liquid yellow phosphorus in a stream of atmospheric oxygen at an oxygen excess ratio of about 1.2 to 1.3 and combustion temperatures of $650-700^{\circ} \mathrm{C}$. The $\mathrm{P}_{2} \mathrm{O}_{5}$ obtained during the oxidation process is directed to the so-called hydration stage, by absorbing phosphoric anhydrite with water and passing the $\mathrm{P}_{2} \mathrm{O}_{5}$ through the water layer from the bottom upwards, at the $\mathrm{P}_{2} \mathrm{O}_{5}$ : water ratio of 1 : 3.3 , converting to $\approx 73 \% \mathrm{H}_{3} \mathrm{PO}_{4}$ to orthophosphoric acid,. for 1.0-1.1 kg / hour of phosphorus consumes 5, 0-6, $5 \mathrm{~kg}$ / h of water (Figure 10). When carrying out studies to study the degree of incomplete oxidation of lower phosphorus oxides $\mathrm{P}_{4} \mathrm{O}_{6}$ and $\mathrm{P}_{4} \mathrm{O}_{10}$ on the temperature, in the presence of dry oxygen, and the determination of the highest yield of phosphorous and phosphoric acids, the results are shown in Figure 11, and the oxidation states of phosphorus in Figure 12.

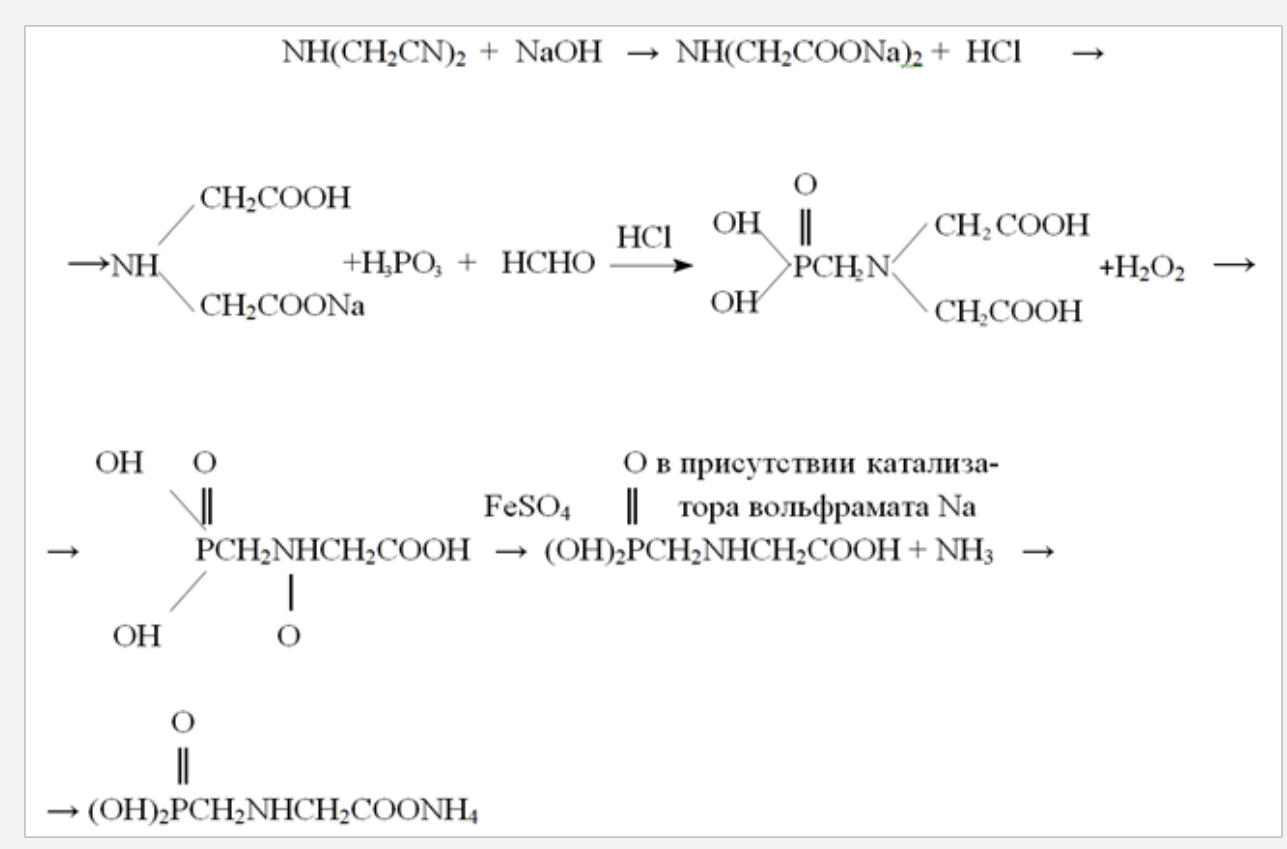

Figure 10.

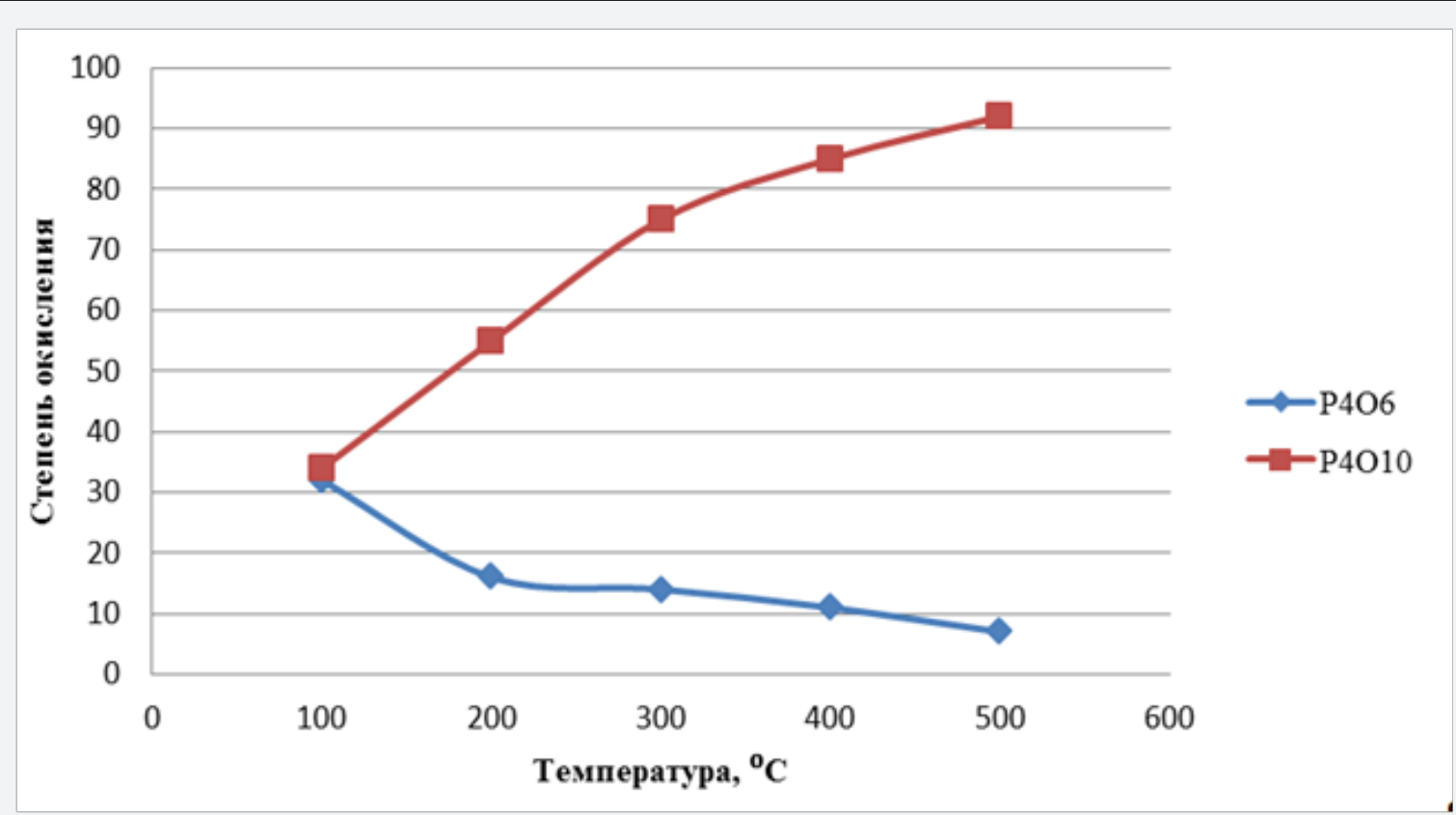

Figure 11: Degree of incomplete oxidation of low oxides of dry phosphorus by air oxygen from temperature. 


\section{Organic and Medicinal Chemistry International Journal}

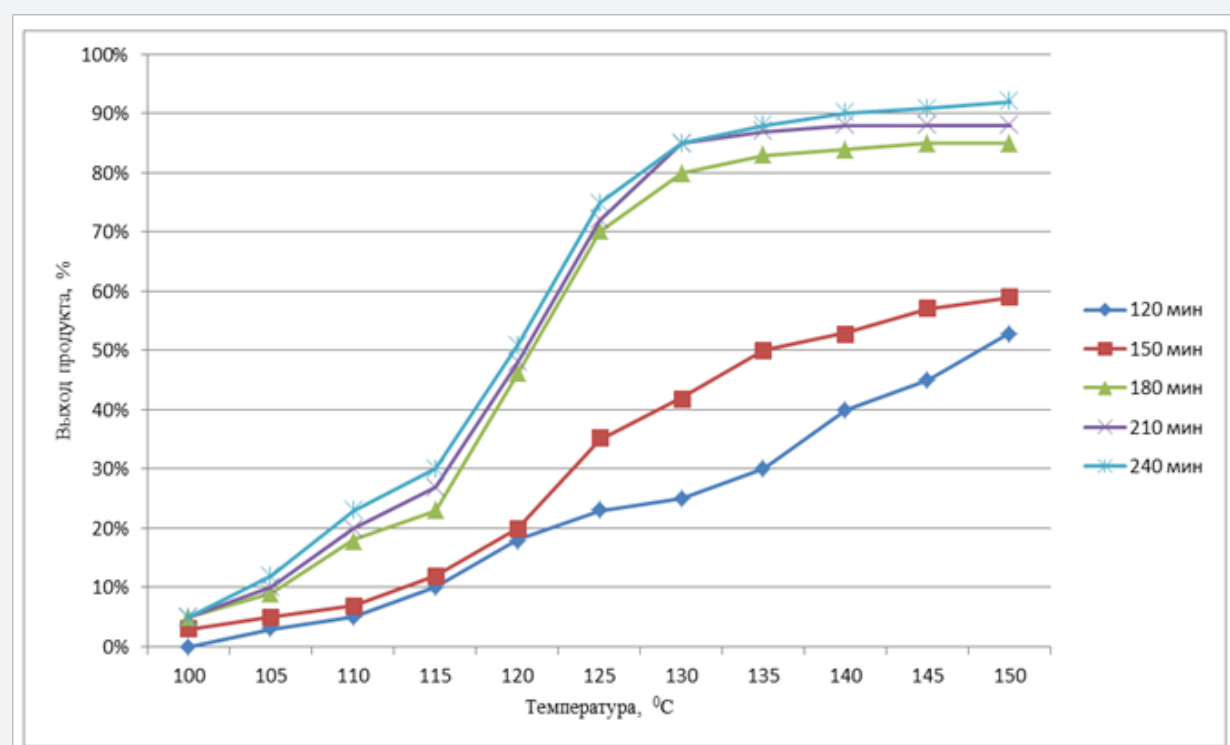

Figure 12: Dependence of glyphosate yield on temperature and process time.

During the tests, the possibility of synthesizing glyphosate from inorganic and organic compounds was established, the results of the analysis of the target product are shown in Figures 13-16. In determining the optimal parameters for the process of obtaining glyphosate from the temperature and time of contacting inorganic and organic compounds, it was found that the optimum temperature for conducting the oxidation-reduction process ranges from 125 to $1400 \mathrm{C}$, and the contacting time is about 180-240 minutes, at which the yield of the product is from
65 to $87 \%$. Information on the chemical composition of samples of glyphosate samples from the parameters of the introduction of the technological process, according to the data obtained with the scanning electron microscope JSM 6390 LV (Japan) are presented in Table 2. Analysis of Table 2 shows that, depending on the process parameters, the glyphosate composition has insignificant differences in phosphorus content from 13.85 to 14.29; chlorine of about 1.7; nitrogen in the range from 14.25 to 14.74; sulfur of about 0.65 and carbon from 27.9 to $28.9 \%$.

\begin{tabular}{l|l}
\hline Fzessert & Becosoñ \% \\
C & 28.21 \\
$\mathrm{~N}$ & 14.74 \\
$\mathrm{O}$ & 40.91 \\
$\mathrm{P}$ & 13.85 \\
$\mathrm{~S}$ & 0.64 \\
$\mathrm{Cl}$ & 1.65 \\
& \\
\hline
\end{tabular}
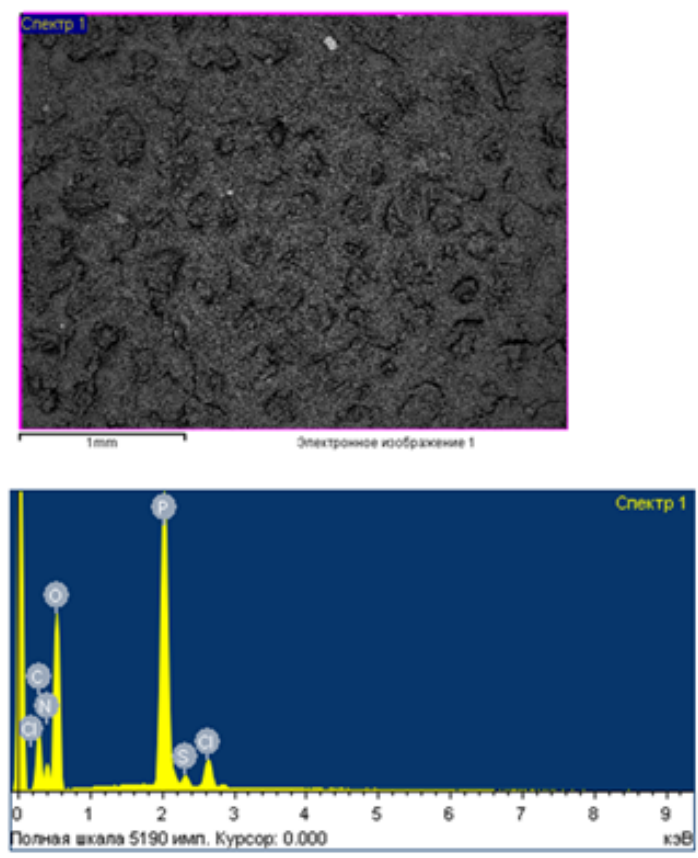

Figure 13: Spectral analysis of the elemental composition of the glyphosate sample (sample 1). 


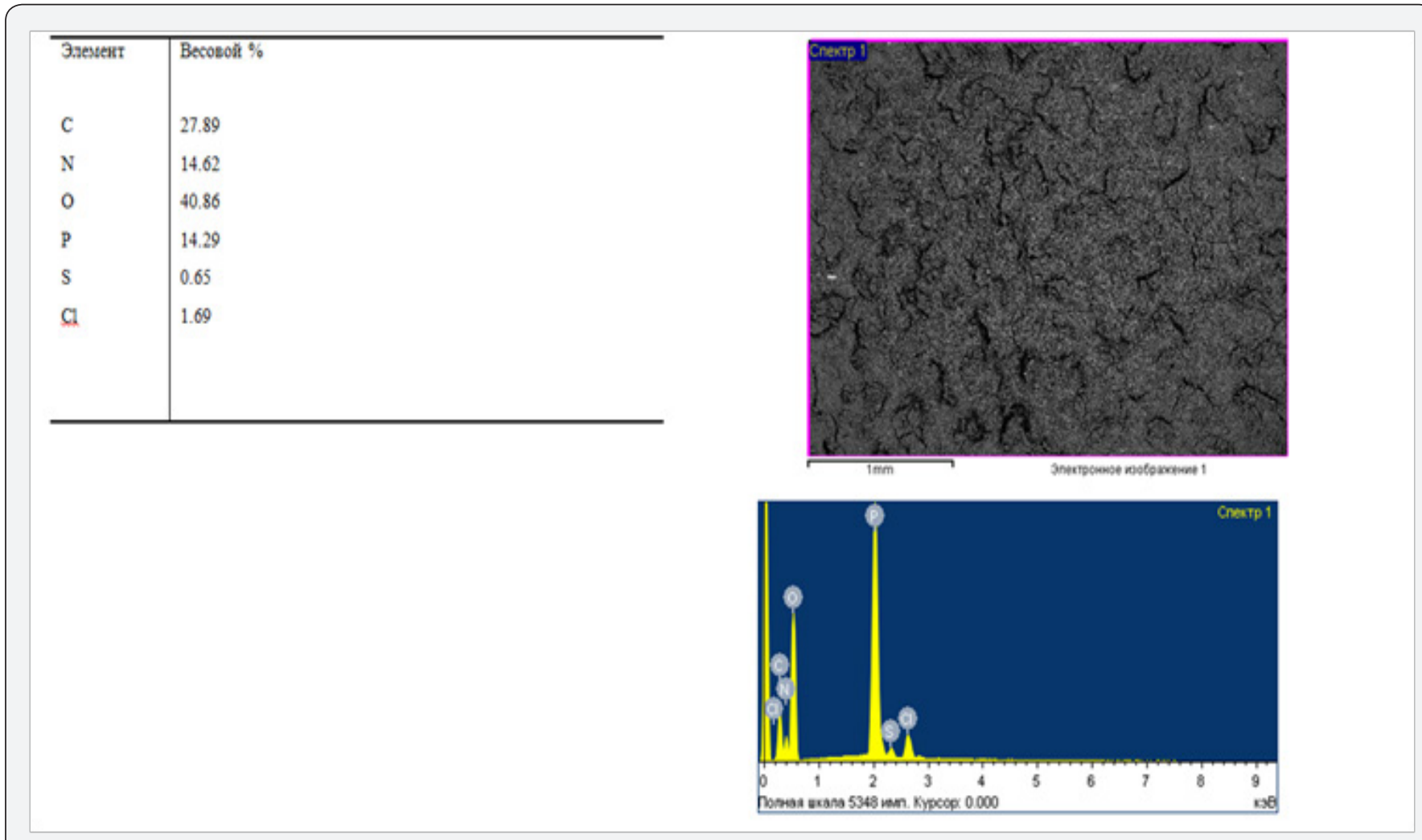

Figure 14: Spectral analysis of the elemental composition of the glyphosate sample (sample 2).

\begin{tabular}{l|l}
\hline Jaevent & Becosof \% \\
$\mathrm{C}$ & 28.92 \\
$\mathrm{~N}$ & 14.25 \\
$\mathrm{O}$ & 40.13 \\
$\mathrm{Na}$ & 0.24 \\
$\mathrm{P}$ & 14.04 \\
$\mathrm{~S}$ & 0.61 \\
$\mathrm{Cl}$ & 1.81 \\
& \\
\hline
\end{tabular}
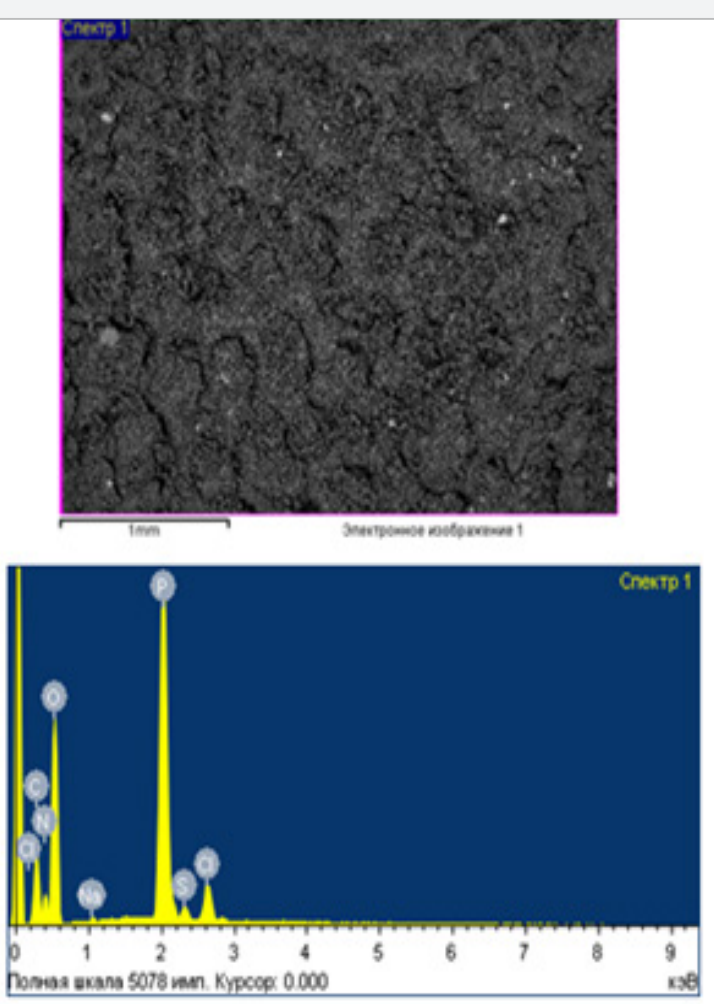

Figure 15: Spectral analysis of the elemental composition of the glyphosate sample (sample 3). 

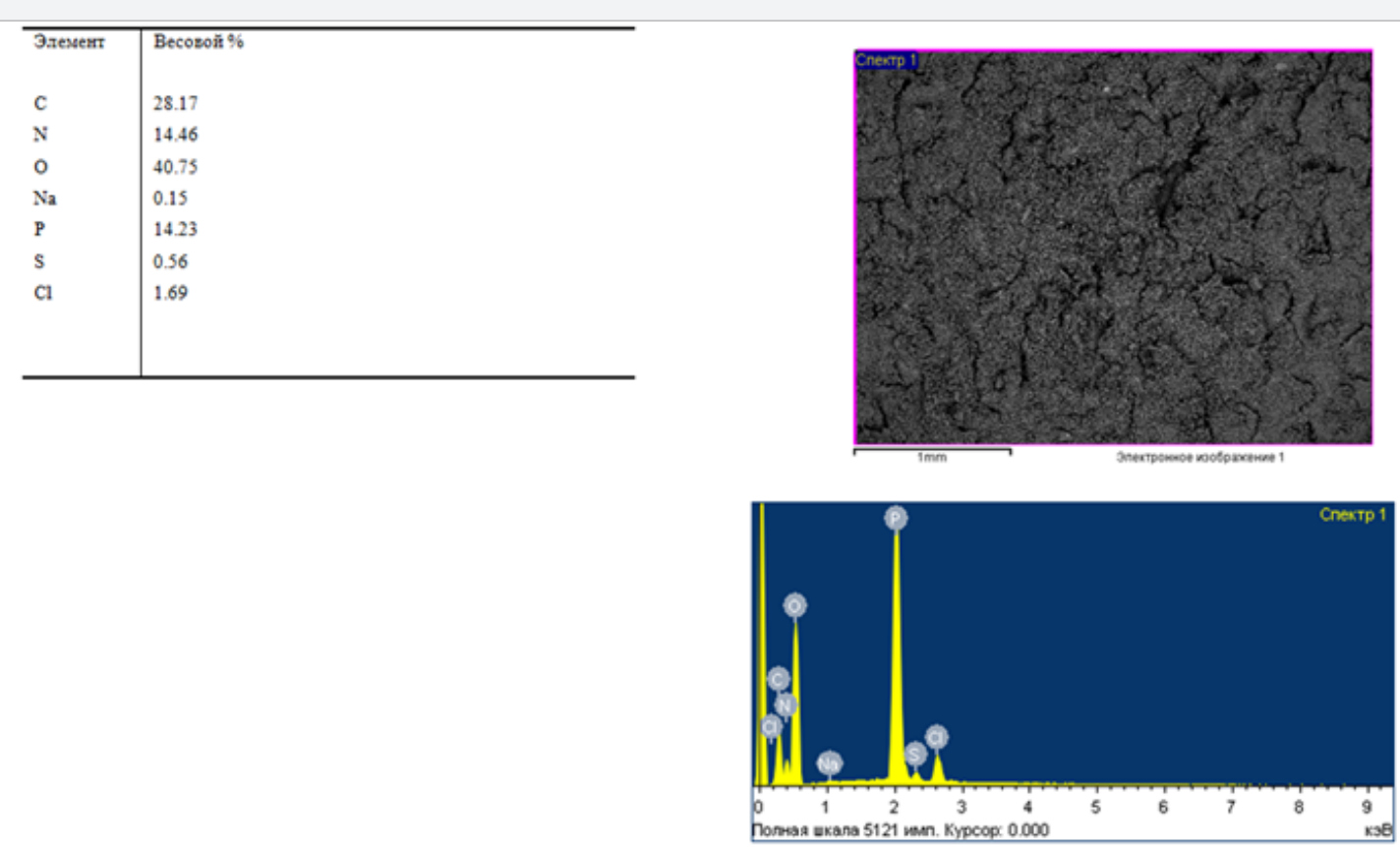

Figure 16: Spectral analysis of the elemental composition of the glyphosate sample (sample 4).

\section{Conclusion}

Based on experimental studies and obtained results of TGA and DSC thermograms, it should be noted that the process of thermal decomposition of ammophos proceeds in six stages. IR spectroscopic analysis of ammophos from the phosphatite deposit of Zhanatas shows that its composition is predominantly ammonium dihydrogenphosphate, $t$. in the IR spectrum of ammophos, all the most intense absorption bands correspond to the absorption bands of ammonium dihydrogen phosphate. In the temperature range corresponding to the second stage (125-277oC), the process of deamonization and dehydration of ammonium dihydrogen phosphate begins, which is accompanied by the polymerization of dihydroorthophosphate ions with the formation of diphosphate, triphosphate and tetraphosphate of anions. Phosphate anions with an average chain length greater than 7 are formed in the third and fourth stages. At temperatures above $450^{\circ} \mathrm{C}$ (the fifth stage), the decomposition of polycondensation products begins, which is accompanied by a greater loss of mass. The total loss of mass upon calcination of ammophos to $1000^{\circ} \mathrm{C}$ is $43.86 \%$, which is higher (39.05\%) for a mixture of dihydrogen phosphate (90 mass\%) and hydrophosphate (10 mass\%), which characterizes the approximate composition of the mofos. Analysis of the chemical composition shows that the content of phosphorus in the test product is 35 to $42 \%$, impurities in it are iron, magnesium, calcium, aluminum, potassium, sodium, manganese and silicon.

Phosphorus-containing sludges formed during electrothermal and phosphorus processing and also their aggregate stability should be considered as joint actions of van der Waals forces of electric interaction of electro-surface and adsorption tension, forming on the surface of sludge particles mechano-energy barriers of calcium, magnesium, fluorine, chlorine, sulfur ions, silicon, phosphorus, sodium, a particle of unreacted carbon, based on metallurgical coke, graphite and various organic compounds of other substances tv. On the basis of this, a hydroclassification method for separating the sludge at washing water rates from 0.001 to $0.01 \mathrm{~cm} / \mathrm{s}$ was proposed, followed by extraction of phosphorus in a temperature range of $250-2600^{\circ} \mathrm{C}$ and condensation in a tower, by irrigation with cold water. It was revealed that in the process of washing phosphorus with water, the phosphorus content increases depending on the washing rate by $10-15 \%$ of its initial content in the sludge. Based on the studies carried out, a technological scheme for the preparation of glyphosate, shown in Figure 8, was developed from inorganic and organic compounds based on diethanolamine, formaldehyde, phosphorous acid.

\section{References}

1. Gabrielova MG, Morozova MA (1953) Production of pesticides. Moscow: Chemistry 216.

2. Zhantasov MK, Altybaev MA, Azimbaev NK, Dzhusenov AU (2005) A method for removing arsenic from dusts of lead-zinc production.

3. Zhantasov KT, Ananiev NI, Zhantasov MK, Zhantasova DM, Niyazbekova RK, et al. (2010) Method for obtaining zinc phosphide.

4. Zhantasov KT, Duisebaev MK, Zhantasov MK, Shapalov ShK, Aibalaeva KD, Begimova AR (2010) Method for removal of arsenic from dusts of lead-zinc production.

5. Melnikov NN (1987) Pesticides. Chemistry, technology and application M Chemistry 712.

6. List of pesticides and agrochemicals allowed for use in the territories of the Russian Federation. Protection and quarantine of plants 539. 
7. Melnikov NN, Novozhilov KV, Belan SR (1995) Pesticides and plant growth regulators/Handbook. Moscow: Chemistry 576.

8. Zhantasov KT, Shalataev SSh, Kadirbayeva AA, Alteev TA, Zhantasov MK, et al. (2014) Current state and prospects for the production of glyphosate. Modern high technology pp. 156-159.

9. Kulik EV, Nikolaychik EA, Selezneva Yu V, Suhanitsky SV, Evtushenkov AN (2015) Creation of plants resistant to glyphosate spring rapeseed using bacterial genes aroAthiO. Proceedings of BSU, Molecular Biology. 10(1): $168-171$.

10. Vedeneev VV (2005) Manufacturers of mineral fertilizers. The profit grows faster than capitalization. Moscow: Bank of Moscow 41.

11. Khamitova RY, Mirsaitova GT (2014) Modern trends in the use of pesticides. Hygiene and Sanitation. 23-26.

12. Wright D, Sandbrink DD, Ratliff PD (2004) Herbicidal liquid and solid concentrate, aqueous herbicidal composition containing glyphosate and pyridine analogue and a method of suppressing or destroying undesirable plants.

13. Lennon PD, Chen K, Arkhanset GB, Glaenser DL, Gillesti DL, et al. (2001) Composition of potassium glyphosate.

14. Clifford Gervik. Development of herbicides for 30 years.

15. Zhantasov KT, Shalatayev SS, Zhantasova D, Mirzayev AA, Kadyrbaeva AA, et al. (2017) Study of using phosphorus slime to obtain glyphosate. Scientific journal Fundamentalisscientam Madrid Spain No. 11 (11): 58-64.
16. GM Wright (1983) Herbicidal compocitions containing glyphosate and a pyridine analog. North Central Weed Control Conference Proceeding. 38: $209-214$

17. Mito N (1999) Herbicidal composition. 209: 12.

18. Prisbylla MP (1983) 4-Hydroxy-5-isopropul-2-methylphenyl trimethyllammonium, 1-piperidine carboxylate salt of N-phosphomethylycine and itsuse as a herbicide. 397: 14.

19. Poss KM (1992) Herbicidal triazolinones. Publ 704: 8.

20. Ganiyu A Jimoh, Ronald J Brinker Storage-stable composition containing txogenous chemical substance and siloxane surfactant. publ 406: 12 .

21. Nakayama K, Kamihara C Liguid herbicide compocition. publ 939: 9.

22. Carlisle SM, Trevors JT (1988) Glyphosatein the environment. Water Air Soil Pollut 39: 409-420.

23. Zhantasov KT, Shalataev SSh, Zhantasov MK, Kalymbetov GE (2015) Investigations of the basics of obtaining glyphosate and its effect on the environment. 55-61.

24. Franz J N-phosphonomethyl-glycine phytotoxicant compositions. Publ p12.

25. Franz JE Salts of N-phosphonomethylglycine. publ 931: 9.

\section{Your next submission with Juniper Publishers will reach you the below assets}

- Quality Editorial service

- Swift Peer Review

- Reprints availability

- E-prints Service

- Manuscript Podcast for convenient understanding

- Global attainment for your research

- Manuscript accessibility in different formats

( Pdf, E-pub, Full Text, Audio)

- Unceasing customer service

Track the below URL for one-step submission https://juniperpublishers.com/online-submission.php 